\title{
Equações de predição da composição química corporal a partir do corte da 9-10-11a costelas de bovinos castrados Nelore ${ }^{1}$
}

\section{Rosemary Laís Galati ${ }^{2}$, Jane Maria Bertocco Ezequiel ${ }^{3}$, Octavio Guilherme da Cruz e Silva ${ }^{4}$, Pedro Henrique Watanabe ${ }^{5}$, Viviane Correa Santos ${ }^{5}$, Bruno Biagioli ${ }^{4}$}

\author{
1 Parte da tese de Doutorado da primeira autora apresentada à FCAV - UNESP, Jaboticabal, São Paulo. Projeto financiado pela FAPESP. \\ 2 Zootecnista, Doutora em Zootecnia pela FCAV - UNESP. \\ ${ }^{3}$ Departamento de Zootecnia na FCAV - UNESP. \\ 4 Zootecnista - FCAV - UNESP. \\ 5 Zootecnista, Bolsista de Apoio Técnico pelo CNPq na FCAV - UNESP.
}

RESUMO - Objetivou-se obter equações de regressão linear simples para estimativa da composição química corporal de novilhos Nelore a partir da composição química do corte da 9-10-1 1 a costelas. Foram utilizados 27 bovinos em confinamento, com 21 a 31 meses de idade e 338,0 a 503,6 kg de peso corporal. Do total, foram abatidos seis animais (referência) ao início do experimento para estimativa da composição química corporal. A composição química em água, proteína, EE e cinzas foi determinada no corte da 9-10-11 a costelas e nos tecidos corporais. As equações de regressão para estimativa do peso de corpo vazio (PCVZ) a partir dos pesos de jejum (PV) e carcaça quente (PCQ) foram PCVZ = 0,8726 PV - 2,7399 e PCVZ = 1,5350 PCQ + 13,598 $\left(\mathrm{R}^{2}=0,98\right)$. O ganho de $1 \mathrm{~kg}$ de PCVZ correspondeu a aproximadamente $1,15 \mathrm{~kg}$ de PV. A porcentagem de água no corpo vazio $(\mathrm{CVz})$ esteve altamente correlacionada às porcentagens de água $\left(\mathrm{R}^{2}=0,98\right)$ e $\mathrm{EE}\left(\mathrm{R}^{2}=0,91\right)$ no corte das costelas. A equação mais indicada foi a desenvolvida a partir da porcentagem de água no corte das costelas $\left(\mathrm{S}_{\mathrm{x}, \mathrm{y}}=0,46\right)$. Verificou-se alta correlação entre a porcentagem de EE no CVz e a porcentagem de $E E\left(R^{2}=0,95\right)$ no corte das costelas, portanto, a equação \%EE CVz $=0,9662 \% \mathrm{EE}$ costelas $+1,5294$ pode ser utilizada para estimativa da composição do CVz em EE. O mesmo ocorreu para a porcentagem de cinzas, sendo recomendada a equação \% MM CVz $=0,5915 \% \mathrm{MM}$ costelas $+0,7619$ $\left(\mathrm{R}^{2}=0,88\right)$. A composição química percentual em água, EE e minerais no corte das $9-10-11^{\text {a }}$ costelas permitiu estimar com acuidade a composição do corpo vazio.

Palavras-chave: bovinos de corte, coeficiente de determinação, corpo vazio, extrato etéreo, proteína

\section{Prediction of chemical body composition by using the $9-10-11^{\text {th }}$ ribs cut on Nellore steers}

\begin{abstract}
The objective of this trial was to develop simple regression equations for estimating the chemical body composition of Nellore steers by using the chemical composition of the 9-10-1 $1^{\text {th }}$ ribs cut. Twenty-seven feedlot Nellore steers varying from 338.0 to $503.6 \mathrm{~kg}$ of BW and from 21 to 31 months of age were used. Six reference animals were slaughtered at the beginning of the trial to estimate the initial chemical body composition. Contents of water, protein, EE, and ash of the 9-10-1 $1^{\text {th }}$ ribs cut and body tissues were determined. Regression equations for estimating empty body weight (EBW) through measurements of BW and hot carcass weight $(\mathrm{HCW})$ were: $\mathrm{EBW}=0.8726 \mathrm{LW}-2.7399$ and $\mathrm{EBW}=1.5350 \mathrm{HCW}+13.598$. The high $\mathrm{R}^{2}$ values (0.98) in both equations indicated that the EBW of Nellore steers can be predicted by using BW and $\mathrm{HCW}$. The gain of $1.0 \mathrm{~kg}$ of EBW corresponded to approximately $1.15 \mathrm{~kg}$ of BW. Water content of empty body (EB) was highly correlated with water $\left(R^{2}=0.98\right)$ and $E E\left(R^{2}=0.91\right)$ contents of the ribs cut; the equation based on the percentage of water in the ribs cut had the best fit $\left(S_{x, y}=0.46\right)$. Because the percentage of EB EE was highly correlated $\left(R^{2}=0.95\right)$ with that of the ribs cut, the equation \% $\mathrm{EB} \mathrm{EE}=0.9662 \%$ ribs $\mathrm{EE}+1.5294$ may be used for estimating EE content of EB. The same was true for ash, which can be estimated by the equation $\% \mathrm{~EB}$ ash $=0.5915 \%$ ribs ash $+0.7619\left(\mathrm{R}^{2}=0.88\right)$. It was concluded that the percentage of water, EE, and ash in the 9-10-1 $1^{\text {th }}$ ribs cut accurately estimated the EB composition of feedlot Nellore steers.
\end{abstract}

Key Words: beef cattle, coefficient of determination, empty body, ether extract, protein

\section{Introdução}

A avaliação nutricional dos ingredientes disponíveis para alimentação permite a formulação de dietas eficientes que possibilitem a expressão do potencial genético do crescimento animal. Entretanto, o aumento da eficiência não se resume somente às informações relacionadas aos aspectos digestivos. O atendimento das exigências 
nu tricionais e o metabolismo de deposição dos nutrientes para formação de tecidos também devem ser eficientes para permitir a maximização do sistema produtivo.

Para que a nutrição e o metabolismo sejam compreendidos como um só sistema, a determinação da composição química e física corporal dos animais torna-se imprescindível, pois, dependendo da categoria animal, as exigências nutricionais poderão ser afetadas, modificando a deposição dos tecidos. Entre os fatores que afetam a composição corporal e as exigências nutricionais, a idade é o que mais influencia a deposição dos tecidos, especialmente o adiposo (Sanz Sampelayo et al., 1987). O sexo e a condição sexual também podem influenciar a composição corporal e as exigências (Garret, 1980; NRC, 1996). Assim, o avanço em idade, associado à castração, faz com que grande parte da energia seja destinada à síntese de gordura, resultando em menores ganhos em proteína corporal (Fontes, 1995), em docorrência da elevada exigência de mantença (ARC, 1980). Desse modo, dependendo da categoria animal, a quantidade de energia nas dietas pode exceder as exigências para crescimento muscular, o que contribui para que o excedente energético seja destinado à síntese de gordura.

Segundo Owens et al. (1995), quando o animal atinge seu peso adulto, o acúmulo tecidual de proteína é muito baixo, embora o turnover protéico seja contínuo, enquanto a deposição de tecido adiposo continua e a retenção de minerais passa a depender da composição do ganho. Maiores deposições de gordura reduzem as deposições de elementos inorgânicos e, conseqüentemente, seus requisitos pelos animais, visto que as concentrações de minerais no tecido adiposo são menores que nos músculos e nos ossos (Silva et al., 2002a). Essas variações metabólicas estão diretamente relacionadas à composição química corporal, o que justifica seu estudo visando obter as exigências $n$ utricionais da diversificada categorial animal brasileira.

A análise de todos os tecidos e do sangue permite conhecer com precisão a composição química corporal dos animais, embora seja um método laborioso e de custo elevado (Garret \& Hinman, 1969; Henrique et al., 2003). A técnica indireta a partir da análise físico-química da 9-10-1 1a costelas surgiu como alternativa à determinação direta a partir da análise de todos os tecidos corporais e tem sido amplamente utilizada e testada a fim de se estabelecerem equações confiáveis para estimativa da composição do corpo vazio (Leme et al., 1994; Véras et al., 2001; Henrique et al., 2003; Paulino et al., 2005).

Neste estudo, objetivou-se desenvolver equações de regressão linear simples para estimativa da composição química corporal de bovinos Nelore a partir da composição química do corte da 9-10-11a costelas.

\section{Material e Métodos}

O experimento foi conduzido no Setor de Confinamento do Departamento de Zootecnia da Faculdade de Ciências Agrárias e Veterinárias, Unesp, Campus de Jaboticabal.

Para a obtenção da composição corporal, foram utilizados 27 bovinos Nelore, castrados (21 a 31 meses de idade e 338,0 a $503,6 \mathrm{~kg}$ de peso corporal), criados em pastagem de Brachiaria humidicola e mantidos confinados em baias individuais $\left(14 \mathrm{~m}^{2}\right)$ com piso de concreto, parcialmente cobertas. O período de avaliação variou de 77 a 118 dias. Os animais foram alimentados duas vezes ao dia (às 8 e às 16 h) em quantidade calculada para ocorrer $10 \%$ de sobras.As rações completas foram formuladas para conter $12,7 \%$ de PB e $70,8 \%$ de NDT na MS e foram fornecidas na proporção volumoso:concentrado de 60:40, sendo a silagem de milho o único volumoso (Tabela 1).

Os animais foram alimentados com cada ração de acordo com seus pesos e, após 21 dias de adaptação, seis novilhos foram submetidos a jejum alimentar e hídrico de 16 horas, sendo pesados no local e abatidos em frigorífico comercial para serem utilizados como referência na determinação da composição química corporal. Os demais foram pesados periodicamente a cada 28 dias e antes de cada abate após jejum completo de 16 horas. O peso mínimo de abate foi estabelecido em $450 \mathrm{~kg}$ e o máximo, em $500 \mathrm{~kg}$. Com isso, pretendeu-se abater pelo menos quatro animais a cada $10 \mathrm{~kg}$ de peso. Assim, foram abatidos bovinos com pesos entre 338,0 e $503,6 \mathrm{~kg}$.

Para obtenção do peso de corpo vazio, o sangue foi coletado, pesado e amostrado imediatamente após a secção na jugular. A determinação da MS do sangue foi feita em estufa com circulação forçada a $55^{\circ} \mathrm{C}$ por 72 horas. Posteriormente, as amostras foram processadas em moinho de bola. O trato gastrintestinal foi recolhido, esvaziado, lavado e pesado. Os órgãos foram compostos por traquéia, pulmão, pâncreas, esôfago, coração, baço, fígado, aparelho urinário e reprodutor, desprezando-se a urina contida na bexiga. A gordura renal-pélvica-inguinal foi retirada e pesada. De todos os animais, recolheram-se e pesaram-se a cabeça, as patas, o couro e a cauda. Após a subtração de todos os componentes, as carcaças foram separadas em duas metades, sendo pesadas e resfriadas por 24 horas. Após oresfriamento, a meia-carcaça esquerda foi dividida em dianteiro, ponta-deagulha e traseiro e separada em tecido muscular, gordura e ossos.

Os componentes utilizados para análise da composição do corpo vazio foram o sangue, a meia-carcaça esquerda, a metade esquerda da cabeça, as patas esquerdas dianteira e traseira, a metade esquerda do couro, os órgãos + gordura 
Tabela 1 - Composição percentual (\%MS) e química das dietas Table 1 - Ingredient (\%DM) and chemical composition of the diets

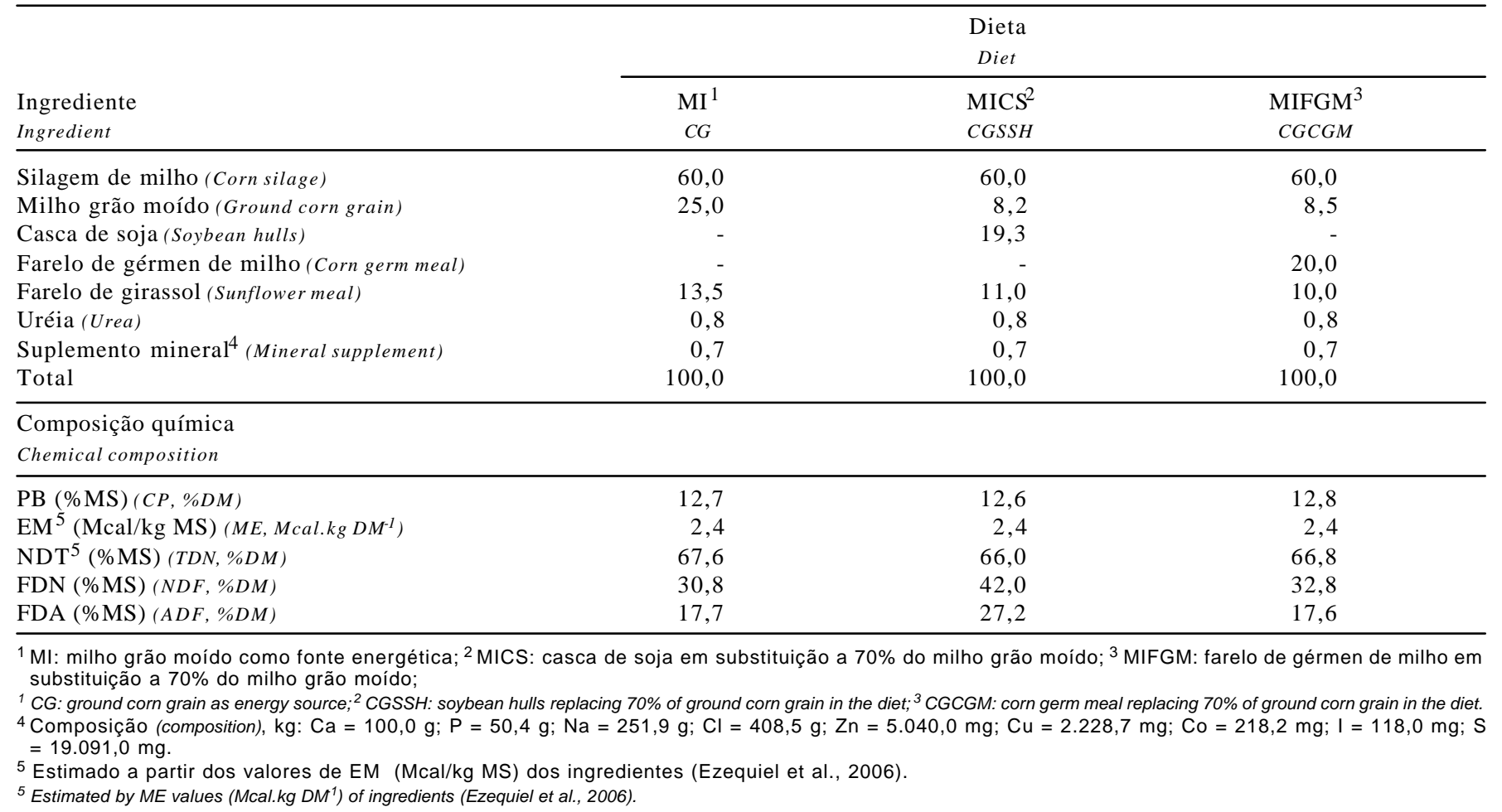

renal-pélvica-inguinal, trato gastrintestinal e cauda. Todos os tecidos foram acondicionados em sacos plásticos e congelados. Com o auxílio de uma serra de fita, cada componente foi reduzido a pedaços menores e moídos em moedor de carne com motor de $10 \mathrm{HP}$ até atingirem estado pastoso. Os componentes de cada animal foram amostrados e liofilizados por até 80 horas, dependendo do componente. Após a liofilização, as amostras foram trituradas em moinho de bola, sem resfriamento.

Na meia-carcaça direita resfriada, retirou-se o corte da seção HH, pela secção transversal da 9-10-1 1a costelas no ponto correspondente a $61,5 \%$ da distância entre a vértebra seccionada e o início da cartilagem da 12ª costela (Hankins \& Howe, 1946). Esse corte foi separado fisicamente em músculo, gordura e ossos e seus componentes foram pesados e analisados separadamente para determinação da composição química do corte.

Após o processamento dos componentes do corpo vazio e do corte da costela, foram determinados os teores de água, em estufa a $105^{\circ} \mathrm{C}$; de proteína $(\mathrm{N}$ x 6,25), em microkjeldahl (AOAC, 1995); de EE, em aparelho tipo Soxhlet durante 15 horas de extração; e os de cinzas, pela queima em forno mufla a $600^{\circ} \mathrm{C}$ por 8 horas. Para determinação dos teores de PB, os componentes contendo elevados teores de gordura foram pré-desengordurados a partir de extrações sucessivas com éter de petróleo segundo método citado por Silva \& Queiroz (2002).

Os resultados foram utilizados para obtenção das equações de regressão linear simples para estimativa da composição química do corpo vazio a partir da composição química do corte da 9-10-11 - costelas.

\section{Resultados e Discussão}

Na Tabela 2 encontram-se as médias para o peso de corpo vazio, o peso de carcaça quente e as composições do corpo vazio e da 9-10-11 a costelas utilizadas na obtenção das equações de regressão para estimativa da composição química corporal de novilhos Nelore.

O constituinte de maior amplitude no corpo vazio e no corte da 9-10-11 a costelas foi o EE, que apresentou elevada correlação $(91,7$ e 94,0\%) com a água (Figura 1). Tendência semelhante foi observada por Alleoni et al. (1997), Leme et al. (2000) e Henrique et al. (2003), independentemente da raça estudada.

Uma vez que o EE é o constituinte mais variável no corpo vazio (CVz), sua subtração possibilitaria a obtenção dos teores de PB e cinzas. Segundo o NRC (1984), a partir da exclusão do constituinte mais variável, ou seja, o EE, a composição da MS desengordurada (MSD) no CVz seria relativamente constante ( $80,2 \%$ de PB e $19,8 \%$ de cinzas). 
Tabela 2 - Peso de corpo vazio, peso da carcaça quente, peso em jejum, porcentagem dos nutrientes no corpo vazio e no corte da 9-10-11a costelas e composição física do corte da 9-10-11a costelas

Table 2 - Empty body weight, hot carcass weight, fasting weight, chemical composition of empty body and 9-10-1 $1^{\text {th }}$ ribs cut, and physical composition of 9-10-1 $1^{\text {th }}$ ribs cut

\begin{tabular}{|c|c|c|c|c|c|}
\hline $\begin{array}{l}\text { Item } \\
\text { Item }\end{array}$ & $\begin{array}{l}\text { Média } \\
\text { Mean }\end{array}$ & $\begin{array}{l}\text { Valor mínimo } \\
\text { Minimum }\end{array}$ & $\begin{array}{l}\text { Valor máximo } \\
\text { Maximum }\end{array}$ & $\begin{array}{l}\text { Desvio-padrão } \\
\text { Standard deviation }\end{array}$ & $\mathrm{CV}(\%)$ \\
\hline $\begin{array}{l}\text { Peso de corpo vazio, } \mathrm{kg} \\
\text { Empty body weight, } \mathrm{kg}\end{array}$ & 387,2 & 293,7 & 440,7 & 46,0 & 11,9 \\
\hline Peso carcaça quente, $\mathrm{kg}$ & 243,4 & 177,0 & 278,5 & 29,6 & 12,2 \\
\hline $\begin{array}{l}\text { Hot carcass weight, } \mathrm{kg} \\
\text { Peso em jejum, kg } \\
\text { Fasting weight, } \mathrm{kg}\end{array}$ & 446,9 & 338,0 & 503,6 & 52,2 & 11,7 \\
\hline
\end{tabular}

Composição química do corpo vazio (\%)

Chemical composition of empty body (\%)

\begin{tabular}{|c|c|c|c|c|c|}
\hline Água (Water) & 53,7 & 50,1 & 62,3 & 3,1 & 5,7 \\
\hline $\mathrm{PB}(C P)$ & 17,9 & 14,9 & 22,4 & 1,9 & 10,8 \\
\hline EE & 25,0 & 13,6 & 30,8 & 5,1 & 20,5 \\
\hline Cinzas (Ash) & 3,4 & 2,5 & 4,7 & 0,5 & 14,5 \\
\hline \multicolumn{6}{|c|}{$\begin{array}{l}\text { Composição química do corte da } 9-10-11^{\text {a }} \text { costelas (\%) } \\
\text { Chemical composition of } 9-10-11^{\text {th }} \text { ribs cut }(\%)\end{array}$} \\
\hline Água (Water) & 53,6 & 50,0 & 62,0 & 2,9 & 5,5 \\
\hline $\mathrm{PB}(C P)$ & 17,8 & 14,6 & 21,5 & 2,1 & 11,7 \\
\hline EE & 24,3 & 11,8 & 31,0 & 5,2 & 21,3 \\
\hline Cinzas (Ash) & 4,4 & 3,0 & 6,3 & 0,8 & 17,6 \\
\hline
\end{tabular}
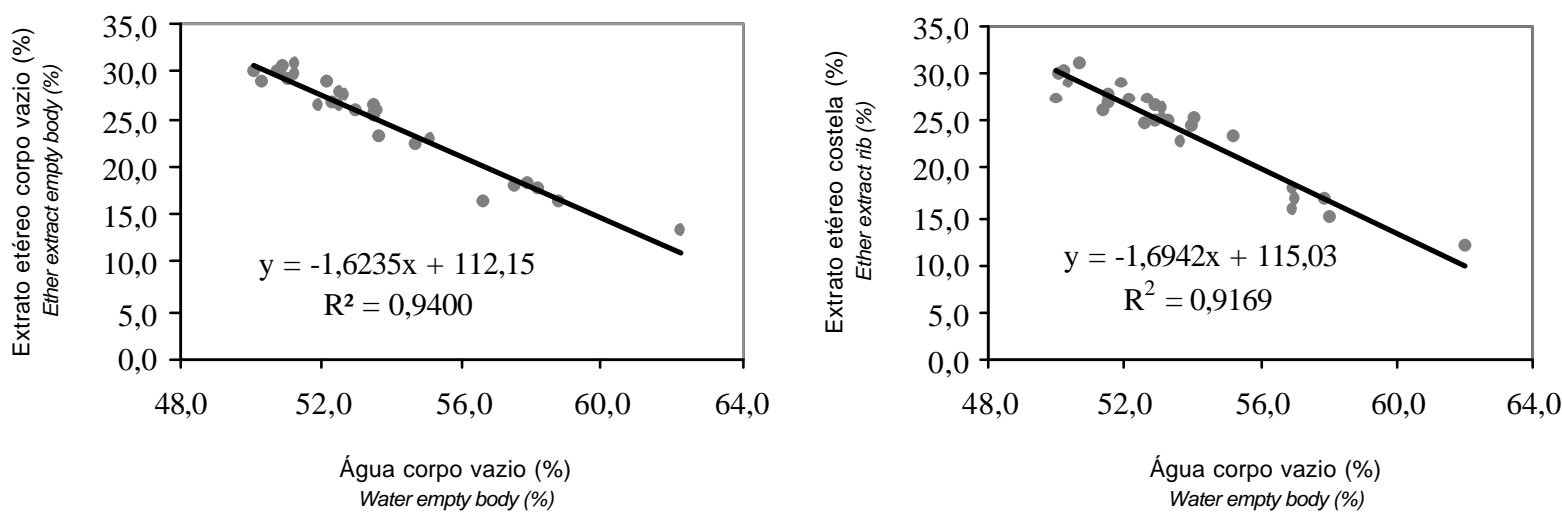

Figura 1 - Porcentagem de EE e água no corpo vazio e no corte da 9-10-11a costelas.

Figure 1 - Relationships between contents of ether extract and water in empty body and 9-10-1 th $^{\text {ribs cut }}$.

Neste trabalho, os teores de PB e cinzas no $\mathrm{CVz}$ desengordurado foram de 84,2 e $15,8 \%$, respectivamente (Tabela 3), superiores aos de 80,1 e 19,9\%, na mesma ordem, obtidos por Alleoni (1995) em bovinos Nelore castrados.

Embora a concentração de PB na MSD observada neste trabalho tenha sido mais elevada que as citadas anteriormente, as relações PB:água e cinzas:água foram muito semelhantes às obtidas por Leme et al. (1994), Alleoni (1995) e Henrique et al. (2003), confirmando que a composição doCVzdesengordurado seria relativamente constante e independente da raça.

Sabendo a composição em proteína e cinzas no $\mathrm{CVz}$ desengordurado, a partir de equações com elevado valor de
$\mathrm{R}^{2}$, pode-se estimar a porcentagem de água e EE no $\mathrm{CVz}$ (Leme et al., 2000; Berndt et al., 2002; Bulle et al., 2002). A vantagem deste procedimento é a praticidade na predição da composição corporal, com significativa diminuição nos gastos em tempo e análises laboratoriais.

Os pesos em jejum (PV) e de carcaça quente (PCQ) foram utilizados para obtenção das equações de regressão para estimativa do peso de corpo vazio (PCVZ):

$\mathrm{PCVZ}=0,8726 \mathrm{PV}-2,7399\left(\mathrm{R}^{2}=0,98 ; \mathrm{S}_{\mathrm{x}, \mathrm{y}}=6,50\right)$

$\mathrm{PCVZ}=1,5350 \mathrm{PCQ}+13,598\left(\mathrm{R}^{2}=0,98 ; \mathrm{S}_{\mathrm{x}, \mathrm{y}}=6,90\right)$

$\mathrm{O}$ valor de $\mathrm{R}^{2}$ para as duas equações foi elevado, indicando que a estimativa do PCVZ de novilhos Nelore a 
Tabela 3 - Composição do corpo vazio desengordurado e relações entre água, PB e cinzas Table 3 - Non-fat empty body composition and protein:water and ash:water ratios

\begin{tabular}{lccrr}
\hline Parâmetro & Média & Valor mínimo & Valor máximo & Desvio-padrão \\
Item & Maximum & CV (\%) \\
\hline Água (water), \% & 71,6 & 67,4 & 74,1 & 1,3 \\
PB (CP), \% & 23,9 & 21,6 & 26,8 & 1,9 \\
Cinzas (ash), \% & 4,5 & 3,4 & 5,6 & 5,1 \\
PB (CP), \%MS & 84,2 & 81,8 & 88,2 & 1,2 \\
Cinzas (Ash), \%MS & 15,8 & 11,8 & 18,2 & 1,4 \\
Proteína:água (Protein:water) & 0,33 & 0,29 & 0,40 & 1,4 \\
Cinzas:água (Ash:water) & 0,06 & 0,05 & 0,08 & 0,023 \\
\hline
\end{tabular}

partir do PV ou do PCQ é adequada. Diversos autores obtiveram boas equações de predição do PCVZ a partir do PV, com valores de $\mathrm{R}^{2}$ variando de 0,94 a 0,98 (Fontes, 1995; Ferreira et al., 1998; Jorge et al. 2000; Véras et al., 2000). Silva et al. (2002b) verificaram que, para bovinos Nelore inteiros, a estimativa do PCVZ poderia ser obtida a partir da relação $\mathrm{PCVZ}=0,8975 \mathrm{PV}$, enquanto Véras et al. (2000) observaram relação PCVZ=PV. Neste trabalho, a partir da regressão de PCVZ em função do peso de jejum, a equação para conversão de ganho de PVCZ em ganho de PV seria:

$$
\mathrm{PV}=1,15(\mathrm{PCVZ}+2,7399)
$$

Usualmente, tem-se estimado o PCVZ a partir do PV, destacando-se, no entanto, a importância da estimativa a partir do PCQ, pois os diferentes regimes alimentares, além da raça, podem influenciar principalmente o tamanho do trato gastrintestinal (TGI). Níveis crescentes de concentrado influenciaram os pesos e comprimentos de órgãos em bezerros holandeses não-castrados (Signoretti et al., 1999). Perón et al. (1993) e Jorge et al. (1999) observaram que animais em restrição alimentar, em comparação a animais alimentados à vontade, apresentaram menor TGI. Diferenças na biometria dos órgãos influenciam diretamente as exigências nutricionais, visto que o turnover protéico aumenta as exigências de mantença (Owens et al., 1993). Owens et al. (1995) observaram que, em raças com aptidão leiteira, as maiores deposições de gordura ocorreram nos componentes viscerais, aumentando a demanda energética para mantença. Diante disso, a utilização do PCQ minimizaria os efeitos de alguns desses fatores que poderiam influenciar a estimativa do PCVZ.

Henrique et al. (2003) utilizaram o PCQ para estimar o PCVZ de tourinhos Santa Gertrudes e encontraram elevados valores de $\mathrm{R}^{2}(0,99)$. Mesmo que os valores de $\mathrm{R}^{2}$ para estimativa do PCVZ a partir do PV tenham sido elevados, a estimativa do PCVZ a partir do PCQ proporciona valores de
$\mathrm{R}^{2}$ maiores, em decorrência da eliminação das diversas fontes de influência (como o tamanho do TGI) presentes no $\mathrm{PV}$, fatores que tornam o PCQ mais indicado.

A porcentagem de água no $\mathrm{CVz}$ esteve correlacionada às porcentagens de água, $\mathrm{PB}, \mathrm{EE}$ e cinzas no corte da 9-1011 a costelas, sendo obtidas as seguintes equações:

\%Água $\mathrm{CVz}=1,0349 \%$ Água costelas $-1,7442$

$\left(\mathrm{R}^{2}=0,98 ; \mathrm{S}_{\mathrm{x}, \mathrm{y}}=0,46\right)$

\%Água $\mathrm{CVz}=1,1385 \%$ PB costelas $+33,4110$

$\left(\mathrm{R}^{2}=0,59 ; \mathrm{S}_{\mathrm{x}, \mathrm{y}}=1,96\right)$

\%Água $\mathrm{CVz}=-0,5661 \% \mathrm{EE}$ costelas $+67,435$

$\left(\mathrm{R}^{2}=0,91 ; \mathrm{S}_{\mathrm{x}, \mathrm{y}}=0,90\right)$

\%\%Água $\mathrm{CVz}=2,7234 \%$ Cinzas costelas $+41,6500$

$\left(\mathrm{R}^{2}=0,46 ; \mathrm{Sx}, \mathrm{y}=2,25\right)$

Observou-se, pelas equações de regressão, que a porcentagem de água do $\mathrm{CVz}$ em relação à de água (Eq.1) e à de EE (Eq.3) do corte da 9-10-1 1a costelas, apresentou elevados valores de $\mathrm{R}^{2}$. Essas equações podem, portanto, ser indicadas para a estimativa da porcentagem de água no $\mathrm{CVz}$. Entre essas duas equações, a mais adequada seria a que utiliza a porcentagem de água no corte da 9-10-11a costelas (Eq.1) em razão de seu elevado valor de $\mathrm{R}^{2}(0,98)$ e do baixo desvio-padrão $(0,46)$ quando comparada à equação 3 . Lanna et al. (1995), Henrique et al. (2003) e Paulino et al. (2005) também obtiveram elevados valores de $\mathrm{R}^{2}$ (acima de 0,90 ) para equações de regressão para a estimativa da composição corporal a partir do corte da 9-10-11 $\underline{a}$ costelas.

A porcentagem de $\mathrm{EE} \mathrm{no} \mathrm{CVz}$ esteve correlacionada às porcentagens de água, $\mathrm{PB}, \mathrm{EE}$ e cinzas presentes no corte da 9-10-11a costelas, obtendo-se as equações:

$\% \mathrm{EE} \mathrm{CVz}=-1,6695 \%$ Água costelas $+114,41$

$\left(\mathrm{R}^{2}=0,90 ; \mathrm{S}_{\mathrm{x}, \mathrm{y}}=0,90\right)$

$\% \mathrm{EE} \mathrm{CVz}=-2,0746 \% \mathrm{~PB}$ costelas $+61,938$

$\left(\mathrm{R}^{2}=0,70 ; \mathrm{S}_{\mathrm{x}, \mathrm{y}}=2,79\right)$ 
$\% \mathrm{EE} \mathrm{CVz}=0,9662 \% \mathrm{EE}$ costelas $+1,5294$

$\left(\mathrm{R}^{2}=0,95 ; \mathrm{S}_{\mathrm{x}, \mathrm{y}}=1,18\right)$

$\% \mathrm{EE} \mathrm{CVz}=-5,1945 \%$ Cinzas costelas $+47,9490$

$\left(\mathrm{R}^{2}=0,60 ; \mathrm{S}_{\mathrm{x}, \mathrm{y}}=3,23\right)$

Assim como observado para o teor de água, o EE no CVz pode ser estimado a partir da água ou do EE no corte da 9-10-11 a costelas. Embora a equação 5 tenha apresentado elevado valor de $\mathrm{R}^{2}(0,90)$, podendo ser indicada para a predição da composição em EE do $\mathrm{CVz}$, a equação mais adequada seria a Eq. 7 por apresentar maior valor de $\mathrm{R}^{2}(0,95)$.

Tão importantes quanto o valor de $\mathrm{R}^{2}$ são a validação da equação para a estimativa da composição do CVz e sua adequação para a categoria animal. Alleoni et al. (1997) utilizaram animais semelhantes aos deste trabalho (novilhos Nelore com 20 a 29,7 meses de idade), cujas composições da 9-10-11 a costelas e do CVz em EE foram de 27,0 e $21,2 \%$, respectivamente.

Para avaliar o poder preditivo da equação 7 deste trabalho, utilizou-se o valor de $27,0 \%$ citado por Alleoni et al. (1997), o que permitiu verificar que esta equação estimou com precisão a composição em EE no CVz (20,8vs $21,2 \%$ ). O mesmo não se aplicou à equação 5 , que superestimou em 30,2\% o teor de EE no CVz. Possíveis explicações poderiam ser tecidas a partir da afirmativa de Pearson et al. (1968) de que a composição corporal somente pode ser estimada a partir das quantidades de água se os animais forem velhos, o que explicaria parte da superestimativa obtida na equação 5 quando a quantidade de água presente no corte das costelas foi utilizada para estimar o EE no CVz. Neste contexto, Moulton (1923), citado por Reid et al. (1955), introduziu o conceito de que haveria maturidade química, ou seja, uma idade partir da qual as quantidades de nutrientes seriam constantes. Com base nesta premissa, pode-se sugerir que, embora houvesse semelhanças entre os animais utilizados por Alleoni et al. (1997) e os deste trabalho, esses animais provavelmente não se encontravam na mesma maturidade fisiológica e química. Para diversificar as equações, dados pertencentes a outros animais, de mesma categoria, criados em condições diferentes das apresentadas neste trabalho poderiam diversificar as equações, corrigindo vícios provenientes de animais muito semelhantes.

Na Figura 2 encontra-se a relação entre a porcentagem de EE no CVz e no corte da 9-10-11a costelas.

A porcentagem de proteína presente no $\mathrm{CVz}$ foi correlacionada às porcentagens de água, PB, EE e cinzas presentes no corte da 9-10-11 a costelas, obtendo-se as equações:

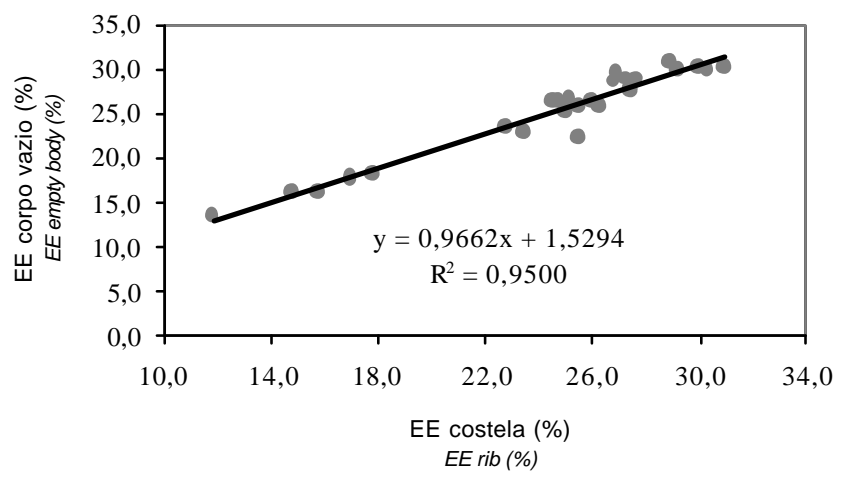

Figura 2 - Porcentagem de EE no corpo vazio e no corte da 9-10-11a costelas.

Figure 2 - Relationship between content of ether extract in empty body and $9-10-11^{\text {th }}$ ribs cut.

\%Prot $\mathrm{CVz}=0,5200 \%$ Água costelas $-9,9052$

$\left(\mathrm{R}^{2}=0,60 ; \mathrm{S}_{\mathrm{x}, \mathrm{y}}=1,22\right)$

\%Prot $\mathrm{CVz}=0,7849 \%$ PB costelas $+3,9690$

$\left(\mathrm{R}^{2}=0,71 ; \mathrm{S}_{\mathrm{x}, \mathrm{y}}=1,05\right)$

\%Prot $\mathrm{CVz}=-0,3255 \% \mathrm{EE}$ costelas $+25,8510$

$\left(\mathrm{R}^{2}=0,75 ; \mathrm{S}_{\mathrm{x}, \mathrm{y}}=0,97\right)$

\%Prot $\mathrm{CVz}=1,8797 \%$ Cinzas costelas $+9,6392$

$\left(\mathrm{R}^{2}=0,56 ; \mathrm{S}_{\mathrm{x}, \mathrm{y}}=1,30\right)$

As regressões relacionando a porcentagem de proteína no CVz e as de água e cinzas no corte da 9-10-11 1 costelas apresentaram baixos valores de $\mathrm{R}^{2}$ (abaixo de 0,60 ), o que impossibilita sua recomendação para estimativa desse componente químico no CVz. Apesar dos maiores valores de $\mathrm{R}^{2}(0,71$ e 0,75$)$ para as equações relacionando a composição química protéica do $\mathrm{CVz}$ e as porcentagens de proteína e EE no corte da 9-10-11a costelas, não se recomenda sua utilização. Outros autores (Lanna et al., 1995; Véras et al., 2001; Henrique et al., 2003) também obtiveram baixos valores de $\mathrm{R}^{2}(0,43$ a 0,65$)$, independentemente da categoria animal, quando desenvolveram equações para predizer a composição protéica do $\mathrm{CVz}$ a partir do corte das costelas.

$\mathrm{Na}$ Figura 3 encontram-se as dispersões de dados utilizados no desenvolvimento das equações de regressão para predição da composição protéica do $\mathrm{CVz}$ em relação à porcentagem de PB no corte da 9-10-11a costelas.

Apesar do baixo valor de $\mathrm{R}^{2}(0,71)$, a dispersão de dados permaneceu próxima à linha de tendência, evidenciando a possibilidade de obtenção de equações adequadas a partir da proteína (Figura 3). Embora sem validade, ao extrair os quatro pontos mais distantes (gráfico B), o valor de $\mathrm{R}^{2}$ elevou de 0,71 para 0,94. Fatores como a coleta, o processamento e, principalmente a homogeneidade das 
amostras, podem interferir na obtenção da composição química corporal, contribuindo para que alguns pontos se distanciem da linha de tendência. Em se tratando de proteína, a homogeneidade das amostras de natureza diversificada seria fator preponderante na obtenção da composição protéica, o que sugeriu que novas observações poderiam ser compiladas contribuindo para obtenção de equações com maior acuidade para a predição desse componente químico.

A proteína foi o componente que menos variou ao longo do desenvolvimento animal, o que indica que a tendência nesses estudos seria de que a porcentagem protéica no corte da 9-10-11 - costelas estimasse satisfatoriamente seu teor no $\mathrm{CVz}$, o que não ocorreu. Recomenda-s e que, para este componente químico, o procedimento mais adequado e preciso para a estimativa no CVz seja a utilização da PB presente na MSD.

A porcentagem de cinzas no $\mathrm{CVz}$ esteve significativamente correlacionada às de água, $\mathrm{PB}, \mathrm{EE}$ e cinzas no corte da 9-10-11a costelas, sendo obtidas as equações:

$\% \mathrm{MM} \mathrm{CVz}=0,1146 \%$ Água costelas $-2,7644\left(\mathrm{R}^{2}=0,45\right.$; $\left.\mathrm{S}_{\mathrm{x}, \mathrm{y}}=0,36\right)$

$\% \mathrm{MM} \mathrm{CVz}=0,1512 \% \mathrm{~PB}$ costelas $+0,6825\left(\mathrm{R}^{2}=0,39\right.$; $\left.\mathrm{S}_{\mathrm{x}, \mathrm{y}}=0,38\right)$

$\% \mathrm{MM} \mathrm{CVz}=-0,0745 \%$ EE costelas $+5,1845\left(\mathrm{R}^{2}=0,60\right.$; $\left.\mathrm{S}_{\mathrm{x}, \mathrm{y}}=0,31\right)$

$\% \mathrm{MM} \mathrm{CVz}=0,5915 \%$ cinzas costelas $+0,7619\left(\mathrm{R}^{2}=0,88\right.$; $\left.\mathrm{S}_{\mathrm{x}, \mathrm{y}}=0,17\right)$

As equações desenvolvidas não foram adequadas para estimar a porcentagem de cinzas do $\mathrm{CVz}$ a partir da porcentagens de água, proteína e EE do corte da 9-10-11a costelas. A porcentagem de cinzas do $\mathrm{CVz}$ foi altamente correlacionada ao teor desse mesmo nutriente no corte da 9-10-11 a costelas $\left(\mathrm{R}^{2}=0,88\right)$, indicando acuidade nessa estimativa. Além da possibilidade de utilização da equação 12 na predição da composição corporal, outra opção seria a porcentagem de cinzas na MSD do CVz (Tabela 3). O desenvolvimento de equações adequadas é fundamental para obtenção das exigências nutricionais. Para isso, é necessário validar essas equações. No intuito de testar o potencial de predição da composição corporal em cinzas a partir da equação 12, utilizou-se o teor de cinzas obtido por Alleoni et al. (1997) no corte das costelas de novilhos Nelore (4,5\%). O valor predito a partir da equação 12 foi de $3,4 \%$ de cinzas no $\mathrm{CVz}$, ou seja, $22,8 \%$ menor que aquele citado (4,2\%) por Alleoni et al. (1997). Seria conveniente avaliar a magnitude dessas diferenças em comparação às exigências nutricionais, pois os valores de $\mathrm{R}^{2}$ de algumas equações descritas neste trabalho indicam que elas são adequadas e recomendáveis, contudo, algumas super ou subestimativas poderão ser obtidas se essas equações forem utilizadas na predição da composição química corporal de animais da mesma categoria. Reforça-se a necessidade da compilação de dados diversificados obtidos a partir de categorias animais semelhantes e provenientes de cria diferente da utilizada neste trabalho, o que, provavelmente, propiciaria equações mais abrangentes, o que, em parte, melhoraria a estimativa sem prejudicar os valores de $\mathrm{R}^{2}$.

Além do desenvolvimento de equações para estimar a composição do $\mathrm{CVz}$ a partir da composição química no corte da 9-10-11 - costelas, os constituintes do CVz poderiam ser correlacionados, possibilitando alternativas rápidas para

A

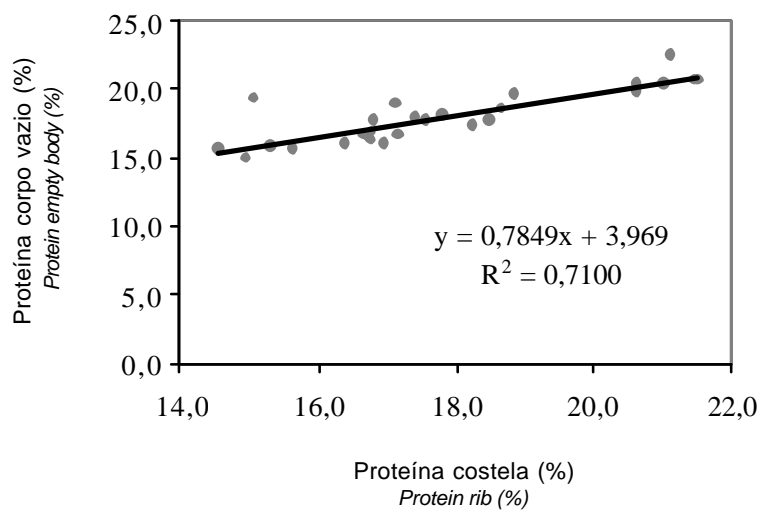

B

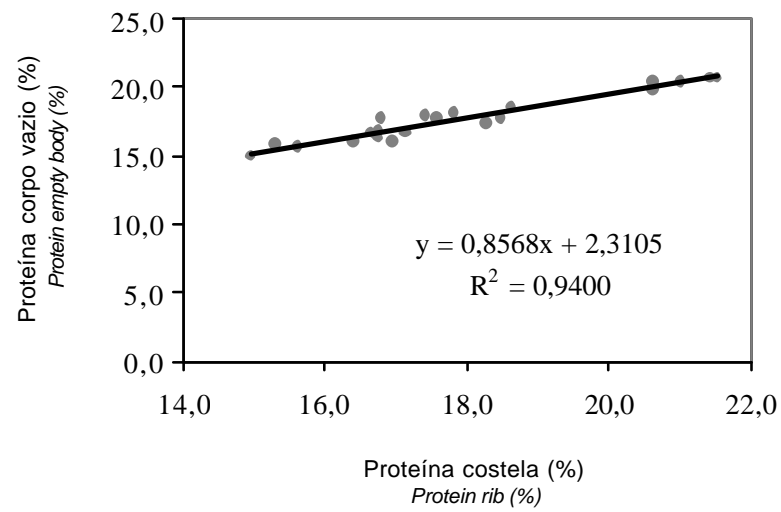

Figura 3 - Composição protéica do corpo vazio e do corte da 9-10-11â costelas (A). Representação gráfica e equação ajustada extraindo-se os pontos mais afastados da linha de tendência (B).

Figure 3 - Relationship between composition of protein in empty body and protein in 9-10-1 $1^{\text {th }}$ ribs cut $(A)$ and graphic representation of the adjusted equation after removal of possible outliers (B). 
predição da composição. Dessa forma, foram desenvolvidas as seguintes equações correlacionando água e EE:

$\% \mathrm{EE} \mathrm{CVz}=-1,6235 \%$ Água $\mathrm{CVz}+112,1500\left(\mathrm{R}^{2}=0,93\right.$;

$\left.\mathrm{S}_{\mathrm{x}, \mathrm{y}}=1,31\right)$

\%Água $\mathrm{CVz}=-0,5772 \% \mathrm{EE} \mathrm{CVz}+68,1130\left(\mathrm{R}^{2}=0,93\right.$; $\left.\mathrm{S}_{\mathrm{x}, \mathrm{y}}=0,78\right)$

A partir da equação 1 , seria obtida a porcentagem de água no CVz e, aplicando-se esse valor estimado na equação 13, obter-se-ia a porcentagem de EE no CVz. Simulando esta observação, a porcentagem estimada de água no $\mathrm{CVz}$ seria 53,7\%. Aplicando-se esse valor na equação 13, a estimativa da porcentagem de EE no CVz seria 24,9\%. O valor real observado para a porcentagem de EE no CVz (Tabela 2) foi de $25 \%$, indicando que esta equação poderia ser adequada para estimar com acurácia e rapidez a composição do $\mathrm{CVz}$ a partir da porcentagem de água no corte da 9-10-11 a costelas.

\section{Conclusões}

As equações de regressão para estimativa do peso de corpo vazio a partir dos pesos de jejum e da carcaça quente de bovinos Nelore castrados (21 a 31 meses de idade, com 338,0 e $503,6 \mathrm{~kg}$ ) foram adequadas.

A composição química em água, EE e cinzas no corte da 9-10-11 - costelas possibilitou que as porcentagens desses componentes nutritivos no corpo vazio fossem estimadas com acuidade.

As regressões obtidas para a estimativa da porcentagem de proteína no $\mathrm{CVz}$ a partir da composição protéica docorte da 9-10-11 a costelas não foram adequadas. No entanto, a utilização do teor de PB na MS desengordurada do corpo vazio pode ser recomendada.

As equações desenvolvidas devem ser utilizadas somente em estudos com animais semelhantes aos deste trabalho, devendo ser validadas previamente para utilização em outras populações.

\section{Literatura Citada}

ALLEONI, G.F. Avaliação da gravidade específica da carcaça, da composição química e física, dos cortes da costela para estimar a composição corporal de novilhos Nelore na fase de acabamento. Jaboticabal: Universidade Estadual Paulista, 1995. 58p. Tese (Doutorado em Zootecnia) Universidade Estadual Paulista, 1995.

ALlEONI, G.F.; LEME, P.R.; BOIN, C. et al. Avaliação da composição química e física dos cortes da costela para estimar a composição química corporal de novilhos Nelore. Revista Brasileira de Zootecnia, v.26, n.2, p.385-390, 1997.

AGRICULTURAL RESEARCH COUNCIL - ARC. The nutrient requirements of ruminant livestock. London: 1980. $351 \mathrm{p}$.
ASSOCIATION OF OFFICIAL ANALYTICAL CHEMISTRY AOAC. Official Methods of analysis. 16.ed. Arlington: Patricial Cunnif, 1995. 1025p.

BERNDT, A.; HENRIQUE, W.; LANNA, D.P.D et al. Milho úmido, bagaço de cana e silagem de milho em dietas de alto teor de concentrado, composição corporal e taxas de deposição dos tecidos. Revista Brasileira de Zootecnia, v.31, n.5, p.21052112, 2002.

BULLE, M.L.M.; RIBEIRO, F.G.; LEME, P.R. et al. Exigências líquidas de energia e proteína de tourinhos de dois grupos genéticos alimentados com dietas de alto teor de concentrado. Revista Brasileira de Zootecnia, v.31, n.1, p.436-443, 2002. Suplemento.

EZEQUIEL, J.M.B.; SILVA, O.G.C.; GALATI, R.L. et al Desempenho de novilhos Nelore alimentados com casca de soja ou farelo de gérmen de milho em substituição parcial ao milho moído. Revista Brasileira de Zootecnia, v.35, n.5, p.569575, 2006.

FERREIRA, M.A.; VALADARES FILHO, S.C.; COELHO DA SILVA, J.F. et al. Composição corporal e exigências líquidas de proteína e energia para ganho de peso de Bovinos $F_{1}$ Simental x Nelore. Revista Brasileira de Zootecnia, v.28, n.2, p.352-360, 1998.

FONTES, C.A.A. Composição corporal, exigências líquidas de nutrientes para ganho de peso e desempenho produtivo de animais zebuínos e mestiços europeu-zebu. Resultados experimentais. In: SIMPÓSIO INTERNACIONAL SOBRE EXIGÊNCIAS NUTRICIONAIS DE RUMINANTES, 1995 Viçosa, MG. Anais... Viçosa, MG: Universidade Federal de Viçosa, 1995. p.419-455.

GARRET, W.N.; HINMAN, N. Re-evaluation of the relationship between carcass density and body composition of beef steers. Journal of Animal Science, v.28, n.1, p.1-5, 1969.

GARRET, W.N. Factors influencing energetic efficiency of beef production. Journal of Animal Science, v.51, n.6, p.1434$1440,1980$.

HANKINS, O.G.; HOWE, P.E. Estimation of the composition of beef carcasses and cuts. Washington: U.S. Department of Agriculture, 1946. 21p. (Technical Bulletin, 926).

HENRIQUE, W.; SAMPAIO, A.A.M.; LEME., P.R. et al. Estimativa da composição química corporal de tourinhos Santa Gertrudes a partir da composição química e física das 9-10-11 a costelas. Revista Brasileira de Zootecnia, v.32, n.3, p.709-718, 2003.

JORGE, A.M.; FONTES, C.A.A.; PAULINO, M.F. et al. Tamanho relativo dos órgãos internos de zebuínos sob alimentação restrita e ad libitum. Revista Brasileira de Zootecnia, v.28, n.2, p.374-380, 1999.

JORGE, A.M.; FONTES, C.A.A.; PAULINO, M.F. et al. Utilização de método indireto para predição da composição química corporal de zebuínos. Revista Brasileira de Zootecnia, v.29, n.6, p.1862-1867, 2000 (supl. 2).

LANNA, D.P.D.; BOIN, C.; ALLEONI, G.F. et al. Estimation of carcass and empty body composition of zebu bulls using the composition of rib cuts. Scientia Agricola, v.52, n.1, p.189197, 1995.

LEME, P.R.; BOIN, C.; ALLEONI, G.F. et al. Estimativa da composição química corporal de novilhos Nelore através do espaço de deutério. Revista da Sociedade Brasileira de Zootecnia, v.23, n.3, p.441-452, 1994.

LEME, P.R.; LANNA, D.P.D.; HENRIQUE, W. et al. Substituição do grão de milho por polpa de citros em dietas com diferentes níveis de concentrado. 2. Taxas de deposição e composição química corporal. Revista Brasileira de Zootecnia, v.29, n.3, p.834-839, 2000.

NATIONAL RESEARCH COUNCIL - NRC. Nutrient requirements of beef cattle. 6.ed. Washington, 1984. 90p.

NATIONAL RESEARCH COUNCIL - NRC. Nutrient requirements of beef cattle. 7.ed. Washington, D.C.: National Academic Press, 1996. 212p. 
OWENS, F.N.; DUBESKI, P.; HANSON, C.F. Factors that alter the growth and development of ruminants. Journal of Animal Science, v.71, n.11, p.3138-3150, 1993.

OWENS, F.N.; GILL, D.R.; SECRIST, D.S. et al. Review of some aspects of growth and development of feedlot cattle. Journal of Animal Science, v.73, n.10, p.3152-3172, 1995.

PAULINO, P.V.R.; COSTA, M.A.L.; VALADARES FILHO, S.C. et al. Validação das equações desenvolvidas por Hankins e Howe para predição da composição da carcaça de zebuínos e desenvolvimento de equações para estimativa da composição corporal. Revista Brasileira de Zootecnia, v.34, n.1, p.327339,2005

PEARSON, A.M.; PURCHAS, R.W.; REINEKE, E.P. Theory and potential usefulness of body density as a predictor of body composition. In: NATIONAL ACADEMY OF SCIENCES (Ed.) Body composition in animals and man. Washington: 1968. p.153-169. (Publication, 1598).

PERON, A.J.; FONTES, C.A.A.; LANA, R.P. et al. Tamanho dos órgãos internos e distribuição da gordura corporal em novilhos de cinco grupos genéticos, submetidos à alimentação restrita e ad libitum. Revista da Sociedade Brasileira de Zootecnia, v.22, n.5, p.813-819, 1993.

REID, J.T.; WELLINGTON, G.H.; DUNN, H.O. Some relationships among the major chemical components of the bovine body and their application to nutritional investigations. Journal of Dairy Science, v.38, n.12, p.1344-1359, 1955.

SANZ SAMPELAYO, M.R.; MUÑOZ, F.J.; EXTREMARA, F.G. et al. Factors affecting pre and pos-weaning growth and body composition in kid goats of the Granadina breed. Animal Production, v.45, n.2, p.233-238, 1987.

SIGNORETTI, R.D.; ARAÚJO, G.G.L.; COELHO DA SILVA, J.F. et al. Características quantitativas das partes do corpo nãointegrantes da carcaça animal e desenvolvimento do trato gastrintestinal de bezerros da raça Holandesa alimentados com dietas contendo quatro níveis de concentrado. Revista Brasileira de Zootecnia, v.28, n.4, p.875-882, 1999.
SILVA, D.J.; QUEIROZ, A.C. Análise de alimentos: métodos químicos e biológicos. 3.ed. Viçosa, MG: Editora UFV, 2002. $235 \mathrm{p}$.

SILVA, F.F.; VALADARES FILHO, S.C.; ÍTAVO, L.C.V. et al Composição corporal e requisitos líquidos e dietéticos de macroelementos minerais de bovinos Nelore não-castrados. Revista Brasileira de Zootecnia, v.31, n.4, p.1849-1864, 2002a.

SILVA, F.F.; VALADARES FILHO, S.C.; ÍTAVO, L.C.V. et al Composição corporal e requisitos energéticos e protéicos de bovinos Nelore, não-castrados, alimentados com rações contendo diferentes níveis de concentrado e proteína. Revista Brasileira de Zootecnia, v.31, n.1, p.503-513, 2002 (supl.) VÉRAS, A.S.C.; VALADARES FILHO, S.C.; SILVA, J.F.C. et al. Composição corporal e requisitos energéticos e protéicos de bovinos Nelore, não-castrados, alimentados com rações contendo diferentes níveis de concentrado. Revista Brasileira de Zootecnia, v.29, n.6, p.2379-2389, 2000.

VÉRAS, A.S.C.; VALADARES FILHO, S.C.; SILVA, J.F.C. et al. Predição da composição corporal de bovinos Nelore e F1 Simental x Nelore a partir da composição química da seção Hankins e Howe (Seção HH). Revista Brasileira de Zootecnia, v.30, n.3, p.1112-1119, 2001 (supl.). 